\title{
Long-term Results of Stellate Ganglion Block in Patients with Olfactory Dysfunction
}

\author{
Department of Anesthesiology and Pain Medicine, College of Medicine, The Catholic University of Korea, Seoul, Korea \\ Ho Sik Moon, MD, Jin Young Chon, MD, Sang Hoon Lee, MD, \\ Yu Mi Ju, MD, and Choon Ho Sung, MD
}

\section{Background:}

Olfactory dysfunction, including anosmia and hyposmia is difficult to treat. Although the mechanism is not well known, stellate ganglion block (SGB) is used to treat olfactory dysfunction. There are no prior studies on the long-term effects of SGB on olfactory dysfunction. The purpose of this study was to evaluate the continuity of therapeutic effects and patient satisfaction with SGB treatment.

\section{Methods:}

This was a follow-up study carried out via a telephonic survey. The olfactory function of the patient was evaluated using a visual analog scale (VAS). We checked VAS three times: VAS-I (pre-treatment VAS), VAS-A (post-treatment VAS), and VAS-C (VAS at follow up telephone survey). We divided the subjects into 2 groups according to their responsiveness to SGB: the responsive (R group) and the unresponsive groups (UR group). Patient satisfaction was evaluated using a Likert scale.

\section{Results:}

Out of the 40 subjects, 37 responded to the telephone survey. In the UR group, there was difference in the olfactory function. However, in the R group, there were significant VAS differences; VAS-I was $9.6 \pm 0.7$, VAS-A was $5.1 \pm 4.2$, and VAS-C was $2.7 \pm 2.7(P<0.05)$. On the Likert scale, patient satisfaction was as follows: grade 1, 17 patients (45.9\%); grade 2, 6 patients (16.2\%); grade 3, 6 patients (16.2\%); and grade 4,8 patients $(21.6 \%)$.

\section{Conclusions:}

SGB is a safe, long-lasting, and effective therapeutic modality for olfactory dysfunction treatment. (Korean J Pain 2013; 26: 57-61)

\section{Key Words:}

anosmia, olfaction, stellate ganglion block, treatment.

Received October 9, 2012. Revised December 20, 2012. Accepted December 21, 2012.

Correspondence to: Choon Ho Sung, MD

Department of Anesthesiology and Pain Medicine, Yeouido St. Mary's Hospital, College of Medicine, The Catholic University of Korea, 10 63-ro, Yeoungdeungpo-gu, Seoul 150-713, Korea

Tel: +82-2-3779-1854, Fax: +82-2-783-0368, E-mail: chsung@catholic.ac.kr

(a) This is an open-access article distributed under the terms of the Creative Commons Attribution Non-Commercial License (http:// creativecommons.org/licenses/by-nc/3.0/), which permits unrestricted non-commercial use, distribution, and reproduction in any medium, provided the original work is properly cited.

Copyright (c) The Korean Pain Society, 2013 


\section{INTRODUCTION}

Although olfactory dysfunction, including anosmia and hyposmia, is not a rare disease, it has often been ignored. However, as the overall standard of living is increasing, more treatments for anosmia and hyposmia are called for. In addition, a growing number of patients suffer from olfactory dysfunction because of the increasing population of elderly people and increases in nasal diseases due to various pollutions, including air pollution and fine dust [1,2] Pignatelli et al. [3] reported that $24 \%$ of the U.S. population suffers from anosmia and hyposmia. In an Asian study, $9-14 \%$ of patients across all age groups reported a problem with olfaction [2]. Olfactory dysfunction can cause weight loss, malnutrition, reduced immunity and deterioration from disease due to intake of spoiled food, loss of appetite, loss of the olfactory defense mechanism for survival, such as escaping from toxic fumes, and reduced life quality through impairing activities of daily living [4-6].

Various therapeutic modalities, such as antibiotics, local or oral steroid administration, endoscopic sinus surgery and anti-allergic drugs, have been proposed to treat olfactory dysfunction. However, these treatments have been reported to produce limited effects. Although the action mechanism of SGB on olfaction is still not well known, there are a few reports that olfactory dysfunction can be treated by SGB $[7,8]$.

There have been no studies on the long-term effects of SGB on olfactory dysfunction. Therefore, we designed this follow-up study for anosmia and hyposmia patients who have received SGB treatment. The purpose of this study was to evaluate the continuity of therapeutic effects and patient satisfaction with the SGB treatment for olfactory dysfunction.

\section{MATERIALS AND METHODS}

This was a clinical observational study approved by the Institutional Review Board. We reviewed medical records of olfactory dysfunction patients who had received SGB and performed a telephone survey to collect data on long-term treatment effects. Participants were recruited from a single hospital. Forty patients received SGB for treatment of olfactory dysfunction between January 2000 and December 2008. They all were diagnosed with anosmia or hyposmia by a butanol threshold test (BTT) and referred to the pain clinic from the ear-nose-throat (ENT) department after various treatments were used with no effect. All patients had received oral or nasal steroids and 2 patients had undergone operation for olfactory dysfunction. SGB was performed 5 times per week for the first two weeks, 3 times per week for the next two weeks. SGB was performed alternately on the right and left sides. When patients were responsive to treatment, that is, when VAS differences were greater than 3, SGB was continued once per week until the symptoms resolved. SGB was conducted using an anterior paratracheal approach at the sixth cervical transverse process, and 6-8 $\mathrm{ml}$ of $1 \%$ mepivacaine was injected slowly. Production of symptoms of Horner's syndrome was regarded as a successful block. We evaluated and recorded each patient's subjective olfactory function before and after treatment on a visual analog scale (VAS): VAS 0 = can smell well; VAS 10 = absence of smell. We divided the subjects into two groups, a responsive group ( $\mathrm{R}$ group) and an unresponsive group (UR group); we defined the R group as those patients with a VAS difference greater than 3, and the UR group as those with a VAS difference less than 3 .

A telephone survey of subjects between January 2011 and February 2011 assessed long-term retention of olfactory function using a VAS and patient satisfaction using a Likert scale. Likert scale: grade 1 = the patient's satisfaction was $<30 \%$; grade 2 = the patient's satisfaction was $30-50 \%$; grade $3=$ the patient's satisfaction was 50-80\%; and grade $4=$ the patient's satisfaction was $>80 \%$. Grades 3 and 4 were defined as "overall satisfied" with SGB treatment. Additionally, adverse effects experienced after treatment were investigated.

All data are presented as mean \pm standard deviation (SD) or frequency. Demographic data from the two groups were compared by using the unpaired $t$-test or chi-square test. The association between VAS improvement and causes of olfactory dysfunction were analysed using the linear by linear association method. Comparison of VAS and patient satisfaction among VAS-I, VAS-A, and VAS-C were performed using a paired $t$-test. A $P<0.05$ was considered significant. Statistical analyses were performed using the SPSS 12.0 (SPSS Inc., Chicago, IL, USA).

\section{RESULTS}

Out of 40 subjects, 37 responded to the telephone survey. Both groups were similar with regard to number, 
age, sex, symptom duration, the ratio of anosmia to hyposmia, follow-up duration, and number of SGB treatment, and also there was no difference in previous treatment between both groups (Table 1). Causes of olfactory dysfunction were trauma, upper respiratory infection (URI), sinonasal disease (SND), congenital, and idiopathic, and there were no statistically significant differences between the 2 groups (Table 2).

In the UR group, there was no difference in pre- and post-treatment VAS scores or between the post-treatment VAS score and those obtained through telephonic survey follow-up. However, in the R group, there were significant differences in pre- and post-treatment VAS scores as well as in the post-treatment VAS score and that obtained by telephonic survey follow-up (Table 3 and Fig. 1). On the

Table 1. Demographic Data

\begin{tabular}{lcc} 
& R group & UR group \\
Number, n (\%) & $15(40.5)$ & $22(59.5)$ \\
Age, yr & $46.3 \pm 16.6$ & $50.6 \pm 12.0$ \\
Sex (M/F) & $6 / 9$ & $10 / 12$ \\
Symptom duration, yr & $1.6 \pm 2.6$ & $4.0 \pm 9.8$ \\
Anosmia/hyposmia & $8 / 7$ & $16 / 6$ \\
Follow up duration, yr & $5.6 \pm 1.6$ & $5.6 \pm 1.9$ \\
Number of SGB treatments, n & $16.9 \pm 16.7$ & $12.6 \pm 18.2$ \\
Previous steroid treatment, n (\%) & $15(100)$ & $22(100)$ \\
Operation, n & 1 & 1 \\
\hline
\end{tabular}

All values are mean \pm standard deviations $(S D)$ or frequency. There are no statistically significant differences between the 2 groups. $R$ group: group that was responsive to $S G B$. UR group: group that was unresponsive to SGB. SGB: stellate ganglion block. Symptom duration: the period between beginningof olfactory symptoms and the start of SGB. Follow-up duration: the period between the conclusion of SGB treatment and the follow-up telephone survey.

Table 2. Causes of Olfactory Dysfunction

\begin{tabular}{lcc} 
Causes & $R$ group $(n=15)$ & UR group $(n=22)$ \\
Trauma & $3(20.0)$ & $6(27.3)$ \\
URI & $4(26.7)$ & $5(22.7)$ \\
SND & $3(20.0)$ & $3(13.6)$ \\
Congenital & $0(0.0)$ & $1(4.5)$ \\
Idiopathic & $5(33.3)$ & $7(31.8)$ \\
\hline
\end{tabular}

All values are numbers and percentage. URI: upper respiratory infection. SND: Sinonasal disease.

Likert scale, patient satisfaction was as follows: grade 1, 17 patients (45.9\%); grade 2, 6 patients (16.2\%); grade 3 , 6 patients (16.2\%); grade 4, 8 patients (21.6\%). Overall satisfaction of the treatment in the $\mathrm{R}$ group was higher than that in the UR group. Only 3 patients showed olfactory function deterioration. One patient experienced complication of the temporary brachial plexus block as a result of the SGB (Table 3).

\section{DISCUSSION}

Olfactory dysfunction, including anosmia and hyposmia, can result from various causes. Allergic or vasomotor rhinitis, chronic sinusitis, nasal polyps, adenoid hypertrophy,

Table 3. Subjective Olfactory Function and Patients' Satisfaction after Previous SGB

\section{$R$ group $(n=15) \quad$ UR group $(n=22)$}

VAS-I

VAS-A

VAS-C

Overall satisfaction, $n$

Symptom aggravation, $n$

Brachial plexus block, $n$

$\begin{array}{cc}9.6 \pm 0.7 & 9.5 \pm 1.0 \\ 5.1 \pm 4.2^{*, \dagger} & 9.2 \pm 1.1 \\ 2.7 \pm 2.7^{*, \dagger} & 9.0 \pm 1.2 \\ 14^{*} & 0 \\ 1 & 2 \\ 0 & 1\end{array}$

All values are mean $\pm S D$ or number. VAS-I: VAS pre-treatment. VAS-A: VAS post-treatment. VAS-C: VAS at follow-up telephone survey. ${ }^{*} P<0.05$ versus UR group. ${ }^{\dagger} P<0.05$ versus VAS-I.

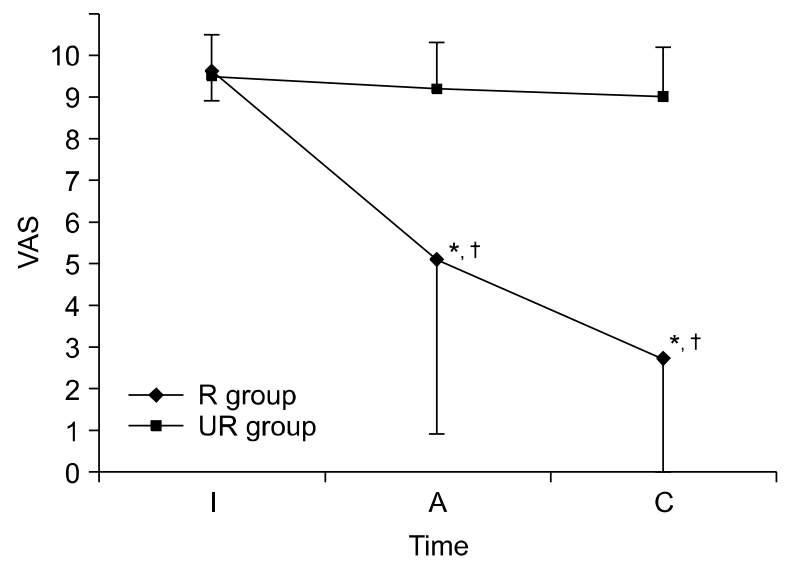

Fig. 1. Changes of subjective olfactory function after SGB. All values are mean $\pm S D$. Subjective olfactory function was measured at different study periods. SGB: stellate ganglion block. VAS: visual analog scale. I: pre-treatment. A: post-treatment. C: at follow-up telephone survey. ${ }^{\star} P<$ 0.05 versus UR group. ${ }^{\dagger} P<0.05$ versus VAS-I. 
URI, head trauma, cigarette smoking, Alzheimer's disease, Parkinson's disease, multiple sclerosis, age, autoimmune disease, drugs, toxins, genetic diseases, such as Kallman's syndrome, and so on $[2,9]$.

Treatment of olfactory dysfunction is different depending on the cause. Causative factors, including nasal polyps, chronic sinusitis, and adenoid hypertrophy can be treated using surgery [2,10]. Olfactory dysfunction related to inflammation shows limited response to oral or topical steroids $[2,7,9,11]$. However, various treatment modalities have no effect on the major causes of olfactory dysfunction, including idiopathic, trauma, toxins, and congenital $[7,8]$. In this study, although sample sizes were too small, there was no difference between the R and UR groups with regard to causes of olfactory dysfunction. Further, since all subjects enrolled in this study did not respond to any other treatment, analyses of SGB effects with regard to cause of the olfactory dysfunction were not appropriate.

SGB is widely considered to be an effective therapeutic modality for various diseases, such as complex regional pain syndrome (CRPS) of the upper limb, pain in the face or head, and so on $[12,13]$. Also, some authors have reported that SGB has an effect on anosmia and hyposmia [7,8]. Lee et al. [8] reported that SGB improved the olfactory sense by $71.1 \%$ in such cases. Generally, the recovery rate of olfactory function depends on the causes of olfactory dysfunction. Olfactory function in the URI group improved in $32 \%$ of the patients, but in only $10 \%$ in the posttraumatic group [14]. However, it may not be useful to compare the results of each study, because olfactory function measurement methods and improvement criteria of olfactory function were different in every study. In this study, we included patients who had not responded to oral or nasal steroids. Therefore, the improvement rate of olfactory function after SGB in this study was different from that in other studies.

The central nervous system (CNS) of the adult mammalian brain is a non-renewable organ. However, Kaplan and Hinds [15] reported that the olfactory bulb and the dentate gyrus of the hippocampus have the ability to regenerate. Adult neurogenesis in the olfactory bulb is regulated by a specialized microenvironment as well as various factors $[16,17]$. Among them, intrinsic factors include activator protein 1 (AP-1), Aristaless-related homeobox-homeodomain transcription factor (Arx), Achaete-scute complex-like 1 (ASCL 1) and so on, and the extrinsic factors include neurotransmitters, such as serotonin, $\gamma$-amino butyric acid (GABA), glutamate, nitric oxide (NO), opioids, cannabinoids, trophic factors, and hormones, such as prolactin, thyroid hormones, neurosteroids, and neuropeptides [16]. Age, odor, sexual signal, stress, and stroke affect neurogenesis in the olfactory bulb [18-21]. In addition, vasculature is closely associated with the migration of newborn cells [22]. Lee et al. [23] showed that superior cervical ganglionectomy enhances regeneration of olfactory receptor cells in mice anosmia induced by zinc sulphate. Therefore, we suggest that the effect of SGB on olfactory dysfunction may be related to an increased blood flow by the sympathetic block. The effects of SGB on blood flow occur no more than $2 \mathrm{~h}$ after SGB [24]. However, the improvement of olfactory function after SGB lasts for a long time as demonstrated in this study. We propose that this is related to neurogenesis in the olfactory nerve under the stimulus of increased blood flow.

Several limitations of this study should be considered when interpreting the results. First, VAS is a subjective parameter $[25,26]$. Although VAS provides validity and reliability in a range of clinical and research applications, olfactory function cannot be evaluated by simple VAS. However, the authors consider that VAS difference can be used to analyse therapeutic effects before and after a single type of treatment. Second, we did not use objective parameters, such as BTT and functional magnetic resonance imaging (fMRI) because of the use of a telephonic survey. Third, the sample size used was relatively small in order to evaluate the effect of SGB and compare the characteristics of both groups. Although there were no statistical differences in symptom durations between the UR and $R$ group, the effects of symptom duration on therapeutic effectiveness of SGB must be considered when analysing the results. Fourth, patient's follow-up durations at the time of telephone survey were different. Finally, our study has a bias because not all patients met the recommended SGB numbers, although there was no statistical significance.

In conclusion, SGB is a simple, safe, long-lasting, and effective therapeutic modality for olfactory dysfunction patients, such as those with anosmia and hyposmia. Further research using objective parameters like BTT and fMRI should be conducted. 


\section{REFERENCES}

1. Schiffman SS. Taste and smell losses in normal aging and disease. JAMA 1997; 278: 1357-62.

2. Gaines AD. Anosmia and hyposmia. Allergy Asthma Proc 2010; 31: 185-9.

3. Pignatelli A, Belluzzi O. Neurogenesis in the adult olfactory bulb. In: The neurobiology of olfaction. Edited by Menini A. Boca Raton (FL), CRC Press. 2010. Chapter 11. Available at http://www.ncbi.nlm.nih.gov/books/NBK55980/.

4. Sivam A, Jeswani S, Reder L, Wang J, DeTineo M, Taxy J, et al. Olfactory cleft inflammation is present in seasonal allergic rhinitis and is reduced with intranasal steroids. Am J Rhinol Allergy 2010; 24: 286-90.

5. Passàli GC, Ralli M, Galli J, Calò L, Paludetti G. How relevant is the impairment of smell for the quality of life in allergic rhinitis? Curr Opin Allergy Clin Immunol 2008; 8: 238-42.

6. Schiffman SS. Taste and smell in disease (second of two parts). N Engl J Med 1983; 308: 1337-43.

7. Moon HS, Lee HJ, Sung CH, Lim SJ, Choi JH. The efficacy of stellate ganglion block in sensorineural anosmia patients unresponsive to steroid therapy. Korean J Pain 2007; 20 : $154-7$.

8. Lee NS, Yoon HR, Park JW, Yum JH, Seo JH, Cho JH, et al. The efficacy of stellate ganglion block in olfactory disorder following upper respiratory tract infection. Korean J OtolaryngolHead Neck Surg 2003; 46: 568-71.

9. Bromley SM. Smell and taste disorders: a primary care approach. Am Fam Physician 2000; 61: 427-36.

10. Hox V, Bobic S, Callebaux I, Jorissen M, Hellings PW. Nasal obstruction and smell impairment in nasal polyp disease: correlation between objective and subjective parameters. Rhinology 2010; 48: 426-32.

11. Mullol J, Obando A, Pujols L, Alobid I. Corticosteroid treatment in chronic rhinosinusitis: the possibilities and the limits. Immunol Allergy Clin North Am 2009; 29: 657-68.

12. Curatolo M, Bogduk N. Diagnostic and therapeutic nerve blocks. In: Bonica's management of pain. 4th ed. Edited by Fishman SM, Ballantyne JC, Rathmell JP. Philadelphia, Lippincott Williams \& Wilkins. 2010, pp 1401-23.

13. Kakuyama M, Toda H, Osawa M, Fukuda K. The bilateral effect of stellate ganglion block on the facial skin blood flow. Reg Anesth Pain Med 2000; 25: 389-92.

14. Reden J, Mueller A, Mueller C, Konstantinidis I, Frasnelli J,
Landis BN, et al. Recovery of olfactory function following closed head injury or infections of the upper respiratory tract. Arch Otolaryngol Head Neck Surg 2006; 132: 265-9.

15. Kaplan MS, Hinds JW. Neurogenesis in the adult rat: electron microscopic analysis of light radioautographs. Science 1977; 197: 1092-4.

16. Hack MA, Saghatelyan A, de Chevigny A, Pfeifer A, AsheryPadan R, Lledo PM, et al. Neuronal fate determinants of adult olfactory bulb neurogenesis. Nat Neurosci 2005; 8: 865-72.

17. Bordey A. Adult neurogenesis: basic concepts of signaling. Cell Cycle 2006; 5: 722-8.

18. Leuner B, Kozorovitskiy Y, Gross CG, Gould E. Diminished adult neurogenesis in the marmoset brain precedes old age. Proc Natl Acad Sci U S A 2007; 104: 17169-73.

19. Rochefort C, Gheusi G, Vincent JD, Lledo PM. Enriched odor exposure increases the number of newborn neurons in the adult olfactory bulb and improves odor memory. J Neurosci 2002; 22: 2679-89.

20. Huang L, Bittman EL. Olfactory bulb cells generated in adult male golden hamsters are specifically activated by exposure to estrous females. Horm Behav 2002; 41: 343-50.

21. Hitoshi S, Maruta N, Higashi M, Kumar A, Kato N, Ikenaka K. Antidepressant drugs reverse the loss of adult neural stem cells following chronic stress. J Neurosci Res 2007; 85: 3574-85.

22. Doetsch F. A niche for adult neural stem cells. Curr Opin Genet Dev 2003; 13: 543-50.

23. Lee NS, Kim BG, Park JM, Park YS, Kim SW, Kim SW, et al. The effect of superior cervical ganglionectomy on recovery of olfaction in induced anosmic mice. Korean J OtolaryngolHead Neck Surg 2005; 48: 1462-7.

24. Yu HG, Chung H, Yoon TG, Yum KW, Kim HJ. Stellate ganglion block increases blood flow into the optic nerve head and the peripapillary retina in human. Auton Neurosci 2003; 109: 53-7.

25. Takebayashi H, Tsuzuki K, Oka H, Fukazawa K, Daimon T, Sakagami M. Clinical availability of a self-administered odor questionnaire for patients with olfactory disorders. Auris Nasus Larynx 2011; 38:65-72.

26. McCormack HM, Horne DJ, Sheather S. Clinical applications of visual analogue scales: a critical review. Psychol Med 1988; 18: 1007-19. 